\title{
Formulation and characterization of self microemulsifying sustained release pellets for breast cancer
}

\author{
Aiswarya Reji and Revathy P Vijayan
}

Dept. of Pharmaceutics, KMCT College of Pharmaceutical Sciences and Research, Kozhikode, Kerala, India

Received: 01-01-2022 / Revised Accepted: 30-01-2022 / Published: 01-02-2022

\begin{abstract}
Purpose of the study: The purpose of the study was to formulate Ormeloxifene loaded selfmicro emulsifying sustained release pellets to enhances aqueous solubility, oral bioavailability and provide sustained release, reduce side effects. Objective: To formulate self microemusifying sustained release pellets by extrusion spheronization. Materials and Methods: The liquid SMEDDS formulations were prepared into self-emulsifying pellets by extrusion spheronization. The components selected for liquid SMEDDS are Oleic acid as Oil, Cremophor RH 40 as Surfactant, Propylene glycol co-surfactant. Self-emulsifying pellets were prepared using MCC PH101 is as spheronizing aid, PVP K 30 as binder, HPMC K100 and Carbopol 974 as sustained release polymer. Prepared liquid SMEDDS were evaluated for particle size, zeta potential, emulsification time, efficiency, robustness to dilution and stability study. Self-micro emulsifying pellets were evaluated for micrometrics properties, percentage yield, drug content, and in vitro drug release studies. Results: Drug content of all the formulations were found to be in the range of $94.98 \%$ to $98.11 \%$. In vitro release studies of all five formulations were done and only the formulations with Carbopol 974P shows sustained release profile. Compared to $2 \%$, and $3 \%$, polymer concentration $5 \%$ (T5) shows good sustained release profile. Conclusion: On the basis of drug content, and in vitro drug release profile the formulation T5 was found to be best suitable to treat breast cancer by sustained release.
\end{abstract}

Key Words: SERM, Sustained release, Extrusion spheronization, Breast cancer, HPMC K 100, Cremophor RH 40.

\section{INTRODUCTION}

The design of oral sustain drug delivery should be primarily aimed to achieve the more predictability and reproducibility to control the drug release, drug concentration in the target tissue and optimization of the therapeutic effect of a drug by controlling its release in the body with lower and less frequent dose. The goal in designing sustained or sustained delivery systems is to reduce the frequency of the dosing or to increase effectiveness of the drug by localization at the site of action, reducing the dose

Address for Correspondence: Aiswarya Reji, Dept. of Pharmaceutics, KMCT College of Pharmaceutical Sciences and Research, Kozhikode, Kerala, India; E-mail: aiswaryareji81@gmail.com

How to Cite this Article: Aiswarya Reji and Revathy P Vijayan. Formulation and characterization of self microemulsifying sustained release pellets for breast cancer. World J Pharm Sci 2022; 10(02): 168-177; https://doi.org/10.54037/WJPS.2022.100202 
required or providing uniform drug delivery. The selected drug category selective estrogen receptor modulators (SERM) act as antagonist on the estrogen receptors of breast tissues. SERMs preferentially bind with these receptors present in the tumour cells and blocks further intracellular signalling pathways thus inhibit proliferation of tumour cells. The selected drug has poor solubility and bioavailability and requires sustained release of drug for effective treatment.

The solid self-micro emulsifying drug delivery system is the appropriate delivery system to provide a sustained release of drug into the body. Self-micro emulsifying drug delivery system are isotropic mixtures of oil, hydrophilic surfactant and or a co surfactant and a solubilized drug ${ }^{[1]}$. They can be encapsulated in hard or soft gelatine capsules. These formulations spontaneously form oil in water nano emulsion upon dilution with water. In the GI tract they are readily dispersed where the motility of the stomach and small intestine provide the gentle agitation necessary for emulsification.

\section{MATERIALS AND METHODS}

Materials: Oleic acid was purchased from NICE chemicals private limited. Cremophor RH 40F Propylene Glycol (BASF - Ludwigshafen). Were used as oil, surfactant, and co- surfactant. Microcrystalline cellulose (Sigma Aldrich chemicals private limited), Aerosil (Wacker) were used as diluent. Poly Vinyl Pyrolidine K30 (BAS Ludwigshafen). Talc (Signet chemical corporation pvt. Ltd.). Ormeloxifene and capsule size No.1 were kindly supplied by HLL Life care pvt. Ltd. Trivandrum.

\section{METHODS}

\section{Preformulation studies}

Solubility of Ormeloxifene: The solubility of Ormeloxifene in various oils, surfactants and cosurfactants was determined. An excess amount of drug $(100 \mathrm{mg})$ of Ormeloxifene was added to each vials containing $3 \mathrm{~mL}$ of the selected vehicles. After sealing of each vials the mixtures were mixed well using a vortex mixer (REMI CM-101 plus) for $10 \mathrm{~min}$ to facilitate the solubilisation of Ormeloxifene. The obtained mixtures were shaken for $24 \mathrm{~h}$ in an orbital shaker (ORBITEK) maintained at $37^{\circ} \mathrm{C}$ and $70 \mathrm{rpm}$ to attain equilibrium. After reaching equilibrium filtered through membrane filter $(0.45 \mu \mathrm{m}$, Whatmann, Maidstone, UK). $1 \mathrm{~mL}$ of filtered solutions were diluted with methanol and drug concentrations were determined using UV -Visible spectrophotometer (Schimadhzu UV-1700 series76) at $\lambda \max 282 \mathrm{~nm}^{[2]}$.
Construction of pseudo-ternary phase diagrams: Based on the solubility study the selected vehicles were developed using water titration method. Surfactant was blended with cosurfactant in the ratio of $1: 1,1: 2$, and $2: 1$. Volume of each surfactant and co-surfactant mixture (Smix) were blended with oil in the ratio of 9:1, 8:2, 7:3, $6: 4,5: 5,4: 6,3: 7,2: 8,1: 9$. Water from $5 \%$ to $95 \%$ of the mixture was added at 10-15 minutes interval to each of the mixture under stirring on magnetic stirrer at $37^{\circ} \mathrm{C}$. After each addition, the mixtures were observed for their appearance (turbid or clear). Turbidity of the samples would indicate the formation of a coarse emulsion, Pseudo ternary phase diagram is constructed using ORIGIN 2018 version 9.1 software. ${ }^{[3], ~[4] ~}$

Design of Experiments: The Design of Experiments (DOE) was used to study the influence of formulation parameters on Critical Quality Attributes of the self-emulsifying drug delivery system. ${ }^{[5],[6]}$ The Central composite face design with 2 factors at 2 levels and 3 central points was constructed in order to study the influence of formulation parameters (independent variables) on the properties (dependent variables) of SMEDDS. The independent variables selected based on risk analysis, and were represented by formulation factors, i.e. Oleic acid concentration (X1) and Smix concentration (X2). The responses of the experimental design were the quality attributes of the SMEDDS. The levels investigated for formulation are based on initial screening experiment/preliminary experiments.

\section{CHARACTERIZATION ORMELOXIFENE LOADED SMEDDS}

OF Droplet Size Analysis and Polydispersibility Index (PDI): $1 \mathrm{~mL}$ of each SMEDDS formula was diluted with $100 \mathrm{~mL}$ distilled water. ${ }^{[7]}$ The droplet size and polydispersibility index of the formed micro emulsions were determined by particle size analyser (Beckman Coulter Delsa Nano S particle size analyser).

Zeta Potential Determination: The zeta potential of the diluted SMEDDS formulae was determined using Zetasizer (Malvern Instruments).

Self-Emulsification Time: In this test, $1 \mathrm{~mL}$ of each formula was introduced into $300 \mathrm{~mL}$ of distilled water maintained at $37 \pm 0.5^{\circ} \mathrm{C}$ in a glass beaker and the contents were mixed gently using a magnetic stirrer rotating at constant speed 100 rpm. ${ }^{[8],[9]}$

Assessment of Efficiency of Self-Emulsification: The self-emulsification efficiency of SMEDDS was evaluated using a standard USP dissolution apparatus type II (Electro lab dissolution tester). 1 
$\mathrm{mL}$ of each formula was added to $500 \mathrm{~mL}$ of distilled water maintained at $37 \pm 0.5^{\circ} \mathrm{C} .{ }^{[10]}$ Ghosh A Gentle agitation was provided by a standard stainless steel dissolution paddle rotating at $50 \mathrm{rpm}$.

The formulation was visually evaluated using the following grading system,

Grade A: Rapidly forming emulsion having a clear or bluish appearance (within $1 \mathrm{~min}$ ).

Grade B: Rapidly forming, slightly less clear emulsion, having a bluish white appearance.

Grade C: Fine milky emulsion that formed within 2 min.

Grade D: Dull, greyish white emulsion having slightly oily appearance that is slow to emulsify (longer than $2 \mathrm{~min}$ ).

Grade E: Formula exhibiting either poor or minimal emulsification with large oil globules present on the surface.

Robustness to Dilution: In order to simulate in vivo dilution behaviour, effect of dilution on emulsion characteristics was studied. This test was performed by diluting $1 \mathrm{~mL}$ of each formula 10 , $100,250 \mathrm{~mL}$ with distilled water, $0.1 \mathrm{~N} \mathrm{Hcl,}$ phosphate buffer pH6.8 The diluted systems were mixed using a magnetic stirrer at $100 \mathrm{rpm}$ and $37^{\circ} \mathrm{C}$.

Thermodynamic Stability Studies: The prepared SMEDDS formulae were subjected to heat-cool cycles, centrifugation and freeze-thaw cycles, where the physical appearances of the formulae were visually observed at the end of each stage.

\section{DEVELOPMENT OF ORMELOXIFENE- SMEDDS PELLETS [11], [12]}

Preparation of Self emulsifying pellets: The selected liquid Ormeloxifene-SMEDDS formulations were used to formulating solid pellets. Accurately weighed ingredients were sieved through sieve no.40 and mixed by geometric means in order to obtain homogenous blend. The solid mixture was wetted by gradual addition of the liquid Ormeloxifene-SMEDDS and proper amount of distilled water to get a damp mass. Wet mass then extruded by caleva multi lab extruder with $1 \mathrm{~mm}$ extruder screen, extruded at a speed of 50 rpm. Extrudates obtained was then spheronizer by a spheronizer at $1200 \mathrm{rpm}$ until to obtain pellets. Then pellets were dried in an oven at $55^{\circ} \mathrm{C}$ for 45 min. (Table 1).

Table 1: Working formula for self-micro emulsifying sustained release pellets

\begin{tabular}{|l|l|l|l|l|l|}
\hline INGREDIENTS (mg) & T1 & T2 & T3 & T4 & T5 \\
\hline Oleic acid (mg) & 20.5 & 20.5 & 20.5 & 20.5 & 20.5 \\
\hline Cremophor RH40(mg) & 26.5 & 26.5 & 26.5 & 26.5 & 26.5 \\
\hline Propylene glycol(mg) & 53 & 53 & 53 & 53 & 53 \\
\hline Ormeloxifene (mg) & 30 & 30 & 30 & 30 & 30 \\
\hline MCC 101 (mg) & 158 & 152 & 155 & 152 & 146 \\
\hline Carbopol 974(mg) & - & - & 6 & 9 & 15 \\
\hline HPMC K100 M(mg) & 3 & 9 & - & - & - \\
\hline PVK K30(mg) & 4.5 & 4.5 & 4.5 & 4.5 & 4.5 \\
\hline Aerosil (mg) & 1.5 & 1.5 & 1.5 & 1.5 & 1.5 \\
\hline Talc (mg) & 3 & 3 & 3 & 3 & 3 \\
\hline Distilled water (mL) & QS. & QS. & QS. & QS. & QS. \\
\hline
\end{tabular}

\section{EVALUATION OF ORMELOXIFENE -} SMEDDS PELLETS [13], [14]

Pellet size distribution and flow properties: Size distribution of pellets was determined by sieving method. Pellets were screened through a set of Standard sieves with pore size of $1.4 \mathrm{~mm}, 1 \mathrm{~mm}$, $850 \mu \mathrm{m}, 710 \mu \mathrm{m}, 600 \mu \mathrm{m}$, and the weight percent of the retained pellets in each sieve was calculated. Pellets flow properties was conducted by using Electro Lab tap density tester USP ETD 1026. To determine bulk density, tapped density, Carr's index, Hausner's ratio.
Percentage yield: All the batches of sustained release pellets prepared by extrusion spheronization were evaluated for percentage yield of the pellets.

Capsule Filling of Pellets: Filling simulations were performed on standard capsule sizes 0-4. Capsules have different capsule size numbers based on their filling capacity.

\section{Characterization of Capsule}

Average weight: Average weight of capsules were evaluated. Weighed 10 capsule individually. The 
empty capsules weighed individually. Net content weights of the individual capsules are calculated.

Estimation of Drug content: Weighed 500mg pellets were powdered by mortar and pestle and accurately weighed the powder contain or equivalent to $50 \mathrm{mg}$ of drug and transfer in to a $100 \mathrm{mLstandard}$ flask. Required quantity of methanol is added to dissolve the drug, and then sonicated for $20 \mathrm{~min}$. After sonication the volume made up to $100 \mathrm{~mL}$ with methanol. Then the solutions were filtered through Whatman filter paper No.1. From this above solution, $10 \mathrm{ml}$ was pipetted out and made up to $100 \mathrm{ml}$ with methanol. Then pipetted out suitable concentration and the absorbance was measured by UV spectrometer at $282 \mathrm{~nm}$.

In vitro drug release: In vitro drug release was determined using USP dissolution test Apparatus 2 (paddle) (ELECTROLAB DISSOLUTION TESTER). The dissolution test was performed using $500 \mathrm{ml}$ of phosphate buffer of $\mathrm{pH} 6.8$ with $0.5 \%$ tween 80 at $75 \mathrm{rpm}$. The temperature of the medium was maintained at $37 \pm 0.5^{\circ} \mathrm{C}$ and the study was carried out for $12 \mathrm{hrs}$. Aliquot of $10 \mathrm{~mL}$ were withdrawn at an interval of $0.5 \mathrm{hr}, 1 \mathrm{hr}, 2 \mathrm{hr}, 4 \mathrm{hr}, 6 \mathrm{hr}$, $8 \mathrm{hr}$, and $12 \mathrm{hr}$. The withdrawn samples were replaced with fresh dissolution medium. The samples were analysed for the drug content by using UV-spectrophotometer at $282 \mathrm{~nm}$.

Drug release kinetics: To find out the mechanism of drug release, the dissolution data of pellets of each batch were treated with different kinetic release equations. The released data were plotted according to zero order, Higuchi and Korsmeyer Peppas method.

\section{RESULTS AND DISCUSSION}

Based on the solubility study among the various oils, higher solubility of Ormeloxifene was found in oleic acid and drug has higher solubility in Cremophor RH40 than tween 80 and among the cosurfactant higher solubility was found in propylene glycol.

Pseudo-ternary phase diagrams was constructed and the size of the micro emulsion region in the diagrams was compared, the larger the size the greater the self-micro emulsification efficiency is in Fig 1. The results showed that the highest micro emulsion region was found in the ratio of $1: 2$ (Smix) when compared to $1: 1$, and 2:1.

The experimental design was evaluated using the ANOVA test. The results of ANOVA test (Table 2) showed a significant influence of the studied factors on droplet size since the $\mathrm{p}$ value for the regression was lower than $0.05(\mathrm{p}=0.046)$, and that the model did not present a significant lack of fit, since the $p$ value for the lack of fit was higher than $0.05(\mathrm{p}=0.086)$

The influence of studied factors on response droplet size is shown in Table 3 and as coefficients of the regression equation plot in Fig 2. According to the mentioned plot, the concentration of Smix had a significant, positive influence on droplet size. Thus, increase in Smix concentration increase the droplet size and decrease in Smix concentration decreases the droplet size. Moreover, there are no significant interactions between the OA, SMIX, $\mathrm{OA}+\mathrm{OA}$, SMIX+SMIX, OA+SMIX as shown in Fig 2.

The results of ANOVA test in Table 4 showed that significant influence of the studied factors on emulsification time, since the $p$ value for the regression was lower than $0.05(\mathrm{p}=0.004)$, and that the model did not present a significant lack of fit, since the $p$ value for the lack of fit was higher than $0.05(\mathrm{p}=0.304)$.

According to the coefficients of the regression equation plot, oleic acid concentration had significant positive influence on emulsification time and Smix concentration had a significant negative influence on emulsification time. Thus, the emulsification time will be higher at high oleic acid concentration and also emulsification time will be lower at high Smix concentration Moreover, there are significant interactions between the OA+ SMIX as shown in Fig 4.

The design space for self-micro emulsifying drug delivery system was determined by the use of Design Space Explorer option from the optimization module of Modde 11.0 Pro software. In order to confirm the validity of the design space, the one formulation (S12) corresponding to the robust set point ( Oleic acid concentration - 153; Smix concentration - 593 ) and one formulation (S13) inside design space (Oleic acid concentration - 120; Smix concentration - 549), one formulation (S14) outside design (Oleic acid concentration - 240 ; Smix concentration - 396 ) was prepared and CQAs were determined, the practical values were compared with the theoretical ones, predicted by the model.

Different batches of Ormeloxifene loaded sustained release self-micro emulsifying pellets were prepared using different polymers such as HPMC $\mathrm{K} 100 \mathrm{M}(1 \%, 3 \%)$, and carbopol 974P (2\%, 3\%, $5 \%$ ) in varying ratios. As per the sieve analysis most of the pellets were retained on sieve number \# 18. Thereby the pellet size was found to be $1 \mathrm{~mm}$. Pellets flow properties was found to be excellent 
flow properties. The amount of therapeutic agent in each capsule was $30 \mathrm{mg}$ and fill volume was fixed as $300 \mathrm{mg}$. Capsule size 1 was selected based on the Table and depending on the bulk density of pellets. The percentage drug content of all prepared formulations i.e. T1-T5 was found to be in the range of $94.98-98.11 \% \mathrm{w} / \mathrm{w}$ is shown in Table 5.

The data of percentage release in $0,0.5,2,4,6,8$, 12, hours is shown in Table: 5.The dissolution profiles of all formulations are shown in Figure: 7. Dissolution study showed that all the formulations with HPMC K100M (T1 and T2) showed drug release within initial $2 \mathrm{hrs}$. The formulations with 3\% Carbopol 974P (T4) showed sustained release of drug for 8 hours and formulation T5 with $5 \%$

Fig.1: Ternary phase diagrams of Smix

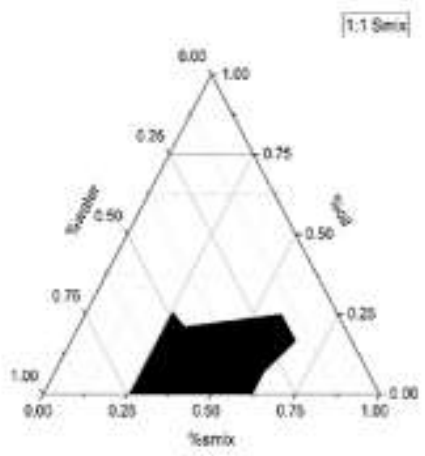

A

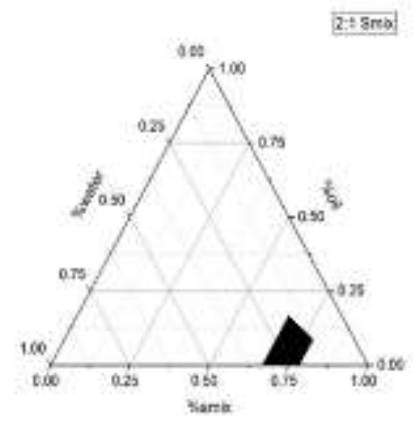

Carbopol 974P showed sustained drug release for 12 hours. Based on the in vitro release, the formulation T5 was finalized as optimized formulation, since it provides maximum sustained release profile.

Based on the interpretation of kinetics data on optimized formulation $\mathrm{T} 5$, highest regression value of 0.9415 was obtained in Zero model in comparison with First order kinetic model.

To determine the mechanism of release, korsemeyar Peppas model was fitted for Formulation T5. The $\mathrm{n}$ values for the formulations T5 was found to be 0.6205 . The result indicates the formulation follows Non- Fickian mechanism of drug release.

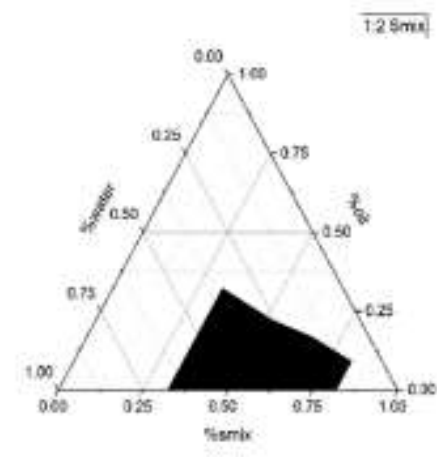

B

Table 2: Experimental design trials data

\begin{tabular}{|l|l|l|l|l|}
\hline Experiment & Oleic acid & Smix & Droplet & Emulsification \\
\hline S1 & 300 & 700 & 88.8 & 75 \\
\hline S2 & 100 & 500 & 24.1 & 80 \\
\hline S3 & 300 & 300 & 66.6 & 300 \\
\hline S4 & 200 & 500 & 61.9 & 61 \\
\hline S5 & 200 & 500 & 63.8 & 40 \\
\hline S6 & 200 & 300 & 41.3 & 63 \\
\hline S7 & 200 & 500 & 71.5 & 82 \\
\hline S8 & 200 & 700 & 105 & 40 \\
\hline S9 & 100 & 300 & 35.4 & 15 \\
\hline S10 & 300 & 500 & 45.4 & 180 \\
\hline S11 & 100 & 700 & 69.6 & 15 \\
\hline
\end{tabular}


Table 3: Analysis of variance for droplet size

\begin{tabular}{|c|c|c|c|c|c|c|c|}
\hline Source & $\begin{array}{l}\text { Degrees of } \\
\text { Freedom }\end{array}$ & $\begin{array}{l}\text { Sum of } \\
\text { Squares }\end{array}$ & $\begin{array}{l}\text { Mean } \\
\text { Square } \\
\text { (variance) }\end{array}$ & $\begin{array}{l}\mathrm{F} \\
\text { value }\end{array}$ & $\begin{array}{l}\mathbf{p} \\
\text { value }\end{array}$ & SD & Comments \\
\hline $\begin{array}{l}\text { Total } \\
\text { corrected }\end{array}$ & 10 & 5581.0 & 558.096 & & & 23.62 & \multirow{5}{*}{$\begin{array}{l}\text { It is evident that } \\
\text { significant } \\
\text { influence on } \\
\text { studied factors } \\
\text { over this response } \\
\text { ( } p<0.05 \text { ) and also } \\
\text { the model does } \\
\text { not have } \\
\text { significant lack of } \\
\text { fit }(p>0.05)\end{array}$} \\
\hline Regression & 5 & 4691.3 & 938.26 & 5.27 & 0.046 & 30.63 & \\
\hline Residual & 5 & 889.7 & 177.93 & & & 13.34 & \\
\hline Lack of Fit & 3 & 838.0 & 279.32 & 10.81 & 0.086 & 16.71 & \\
\hline Pure error & 2 & 51.7 & 25.84 & & & 5.08 & \\
\hline
\end{tabular}

Fig. 2: Influence of formulation factors on the droplet size presented scaled and centered coefficient plots

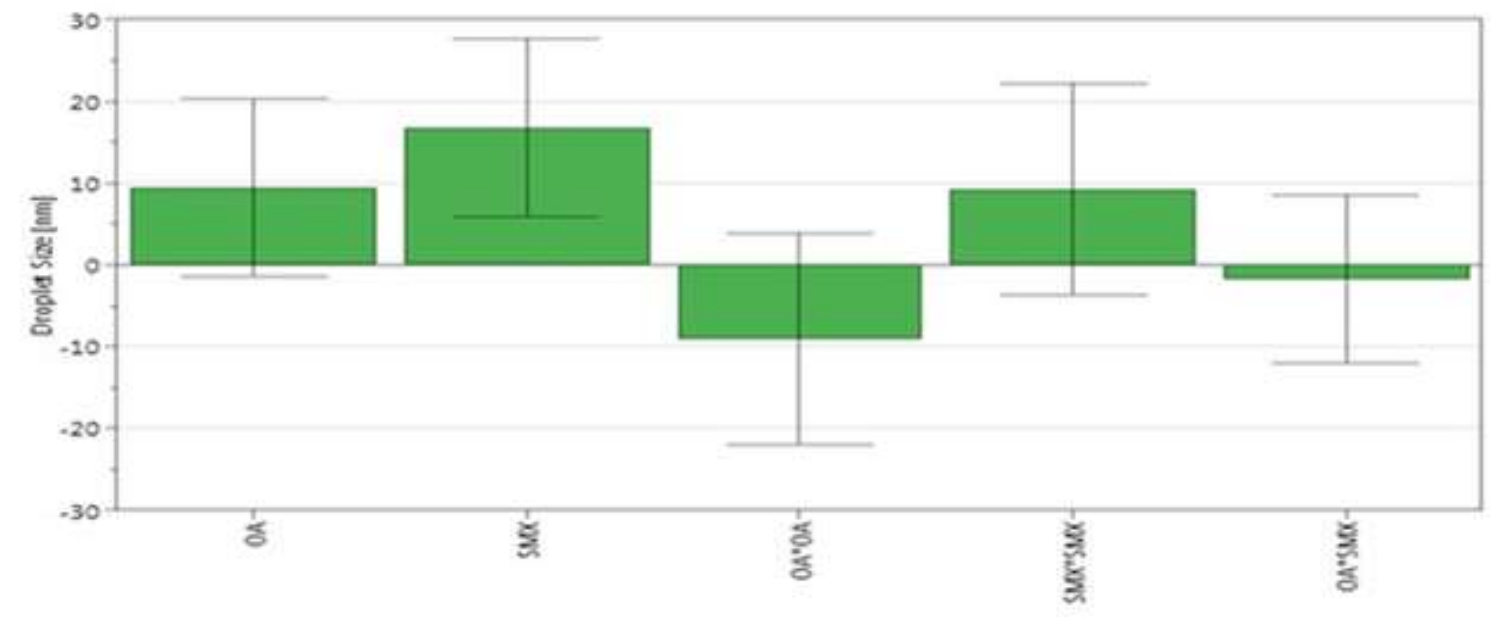

Fig. 3: Contour Plot to study the effect of oleic acid and S-mix on droplet size

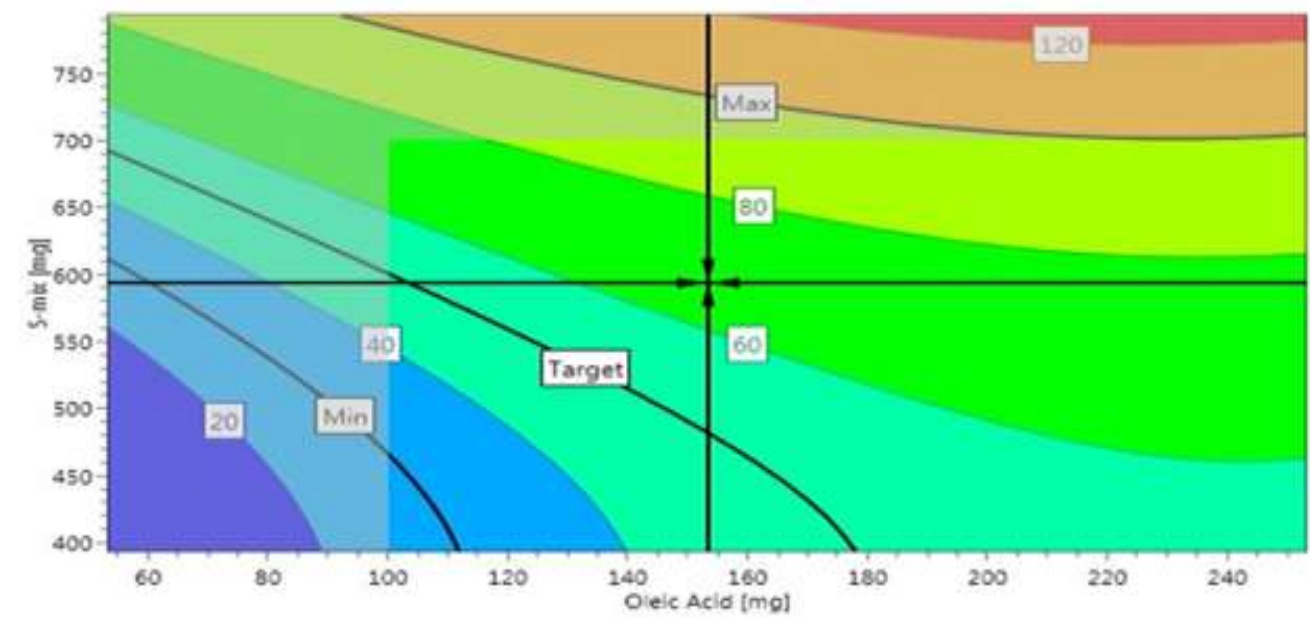


Aiswarya et al., World J Pharm Sci 2022; 10(02): 168-177

Table 4: Analysis of variance for emulsification time

\begin{tabular}{|c|c|c|c|c|c|c|c|}
\hline Source & $\begin{array}{l}\text { Degrees of } \\
\text { Freedom }\end{array}$ & $\begin{array}{l}\text { Sum of } \\
\text { Squares }\end{array}$ & $\begin{array}{l}\text { Mean } \\
\text { Square } \\
\text { (variance) }\end{array}$ & $\begin{array}{l}\text { F } \\
\text { value }\end{array}$ & $\begin{array}{l}\mathbf{p} \\
\text { value }\end{array}$ & SD & Comments \\
\hline $\begin{array}{l}\text { Total } \\
\text { corrected }\end{array}$ & 10 & 73188.9 & 7318.89 & & & 85.55 & \multirow{5}{*}{$\begin{array}{l}\text { It is evident } \\
\text { that } \\
\text { significant } \\
\text { influence on } \\
\text { studied } \\
\text { factors over } \\
\text { this response } \\
\text { ( p <0.05) and } \\
\text { also the } \\
\text { model does } \\
\text { not have } \\
\text { significant } \\
\text { lack of fit } \\
(p>0.05)\end{array}$} \\
\hline Regression & 5 & 69086.7 & 13817.30 & 16.84 & 0.004 & 117.55 & \\
\hline Residual & 5 & 4102.2 & 820.44 & & & 28.64 & \\
\hline Lack of Fit & 3 & 3220.2 & 1073.40 & 2.43 & 0.304 & 32.76 & \\
\hline Pure error & 2 & 882.0 & 441.00 & & & 21.00 & \\
\hline
\end{tabular}

Fig. 4: Influence of formulation factors on the emulsification time presented scaled and centered coefficient plots

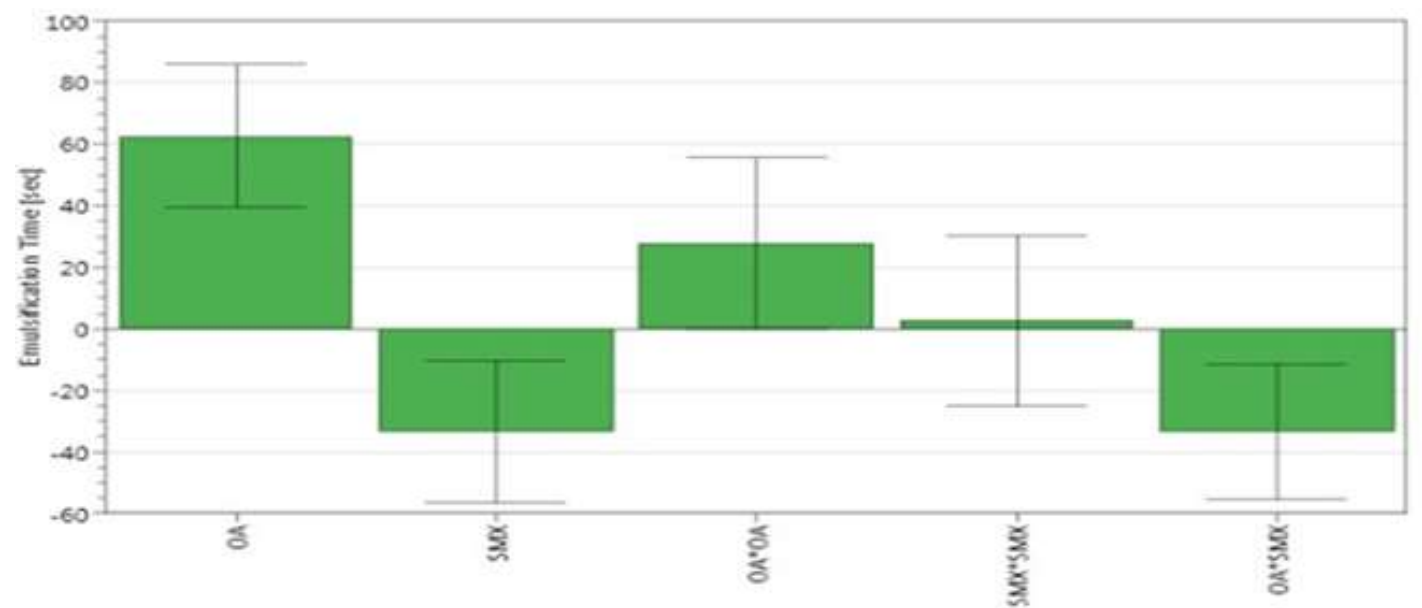

Fig. 5: Contour Plot to study the effect of oleic acid and S-mix on emulsification time

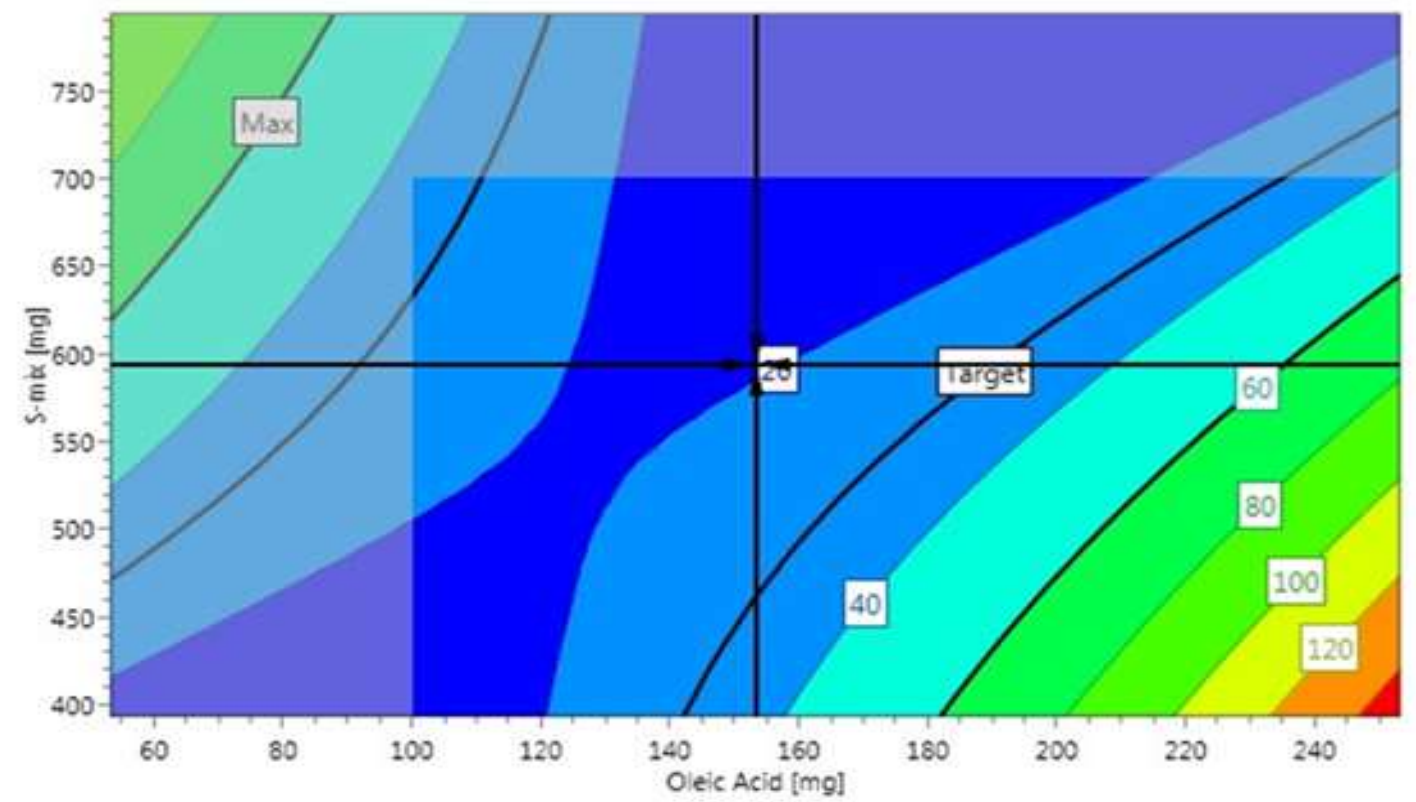


Fig. 6: The design space and proven acceptable range (PAR)

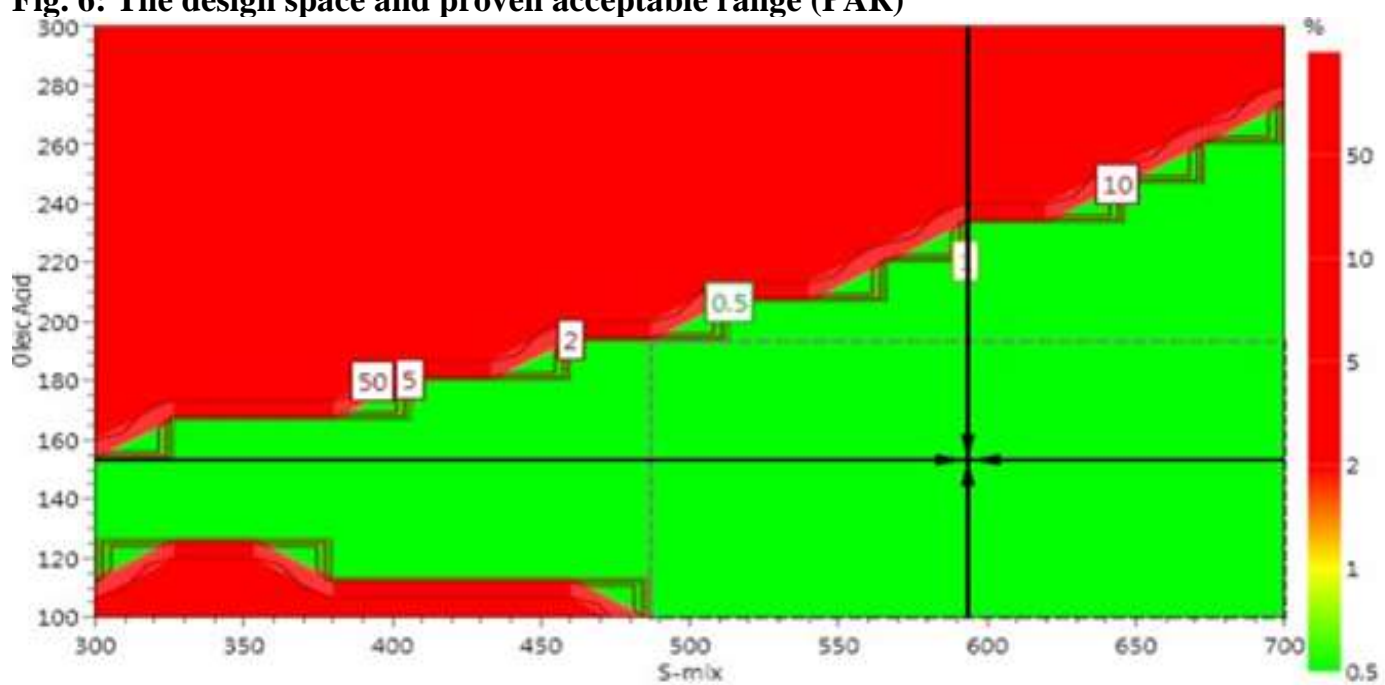

The green area represents the design space and

this area, factor values can vary independently from each other, while the obtained product will meet each point from this area predicts, with a low probability of failure under $1 \%$, a possible SMEDDS formulation that would possess the described CQAs. The dotted frame inside the design space is the design space hypercube, which defines the proven acceptable range (PAR). Within the specified quality target. The cross-hairs that can be noticed in the figures indicate the robust set point, representing the input values that will predict, with the highest statistical values, a result within specifications.

Table 5: Percentage drug content of all prepared formulations

\begin{tabular}{|l|l|}
\hline Formulation & $\begin{array}{l}\text { Percentage drug content } \\
(\%)\end{array}$ \\
\hline T1 & 95.60 \\
\hline T2 & 94.98 \\
\hline T3 & 93.59 \\
\hline T4 & 96.75 \\
\hline T5 & 98.11 \\
\hline
\end{tabular}

In vitro drug release study

Table 6: In vitro release profile of T1-T5

\begin{tabular}{|l|l|l|l|l|l|}
\hline \multirow{2}{*}{ Time } & \multicolumn{5}{|l}{ Cumulative \% of drug release } \\
\cline { 2 - 6 } & T1 & T2 & T3 & T4 & T5 \\
\hline 0 & 0 & 0 & 0 & 0 & 0 \\
\hline 0.5 & 91 & 44 & 75 & 63 & 57 \\
\hline 1 & 98 & 71 & 91 & 77 & 66 \\
\hline 2 & & 93 & 97 & 92 & 76 \\
\hline 4 & & & 98 & 96 & 85 \\
\hline 6 & & & & 98 & 95 \\
\hline 8 & & & & 99 & 96 \\
\hline 12 & & & & & 99 \\
\hline
\end{tabular}


Fig. 7: In vitro release profiles

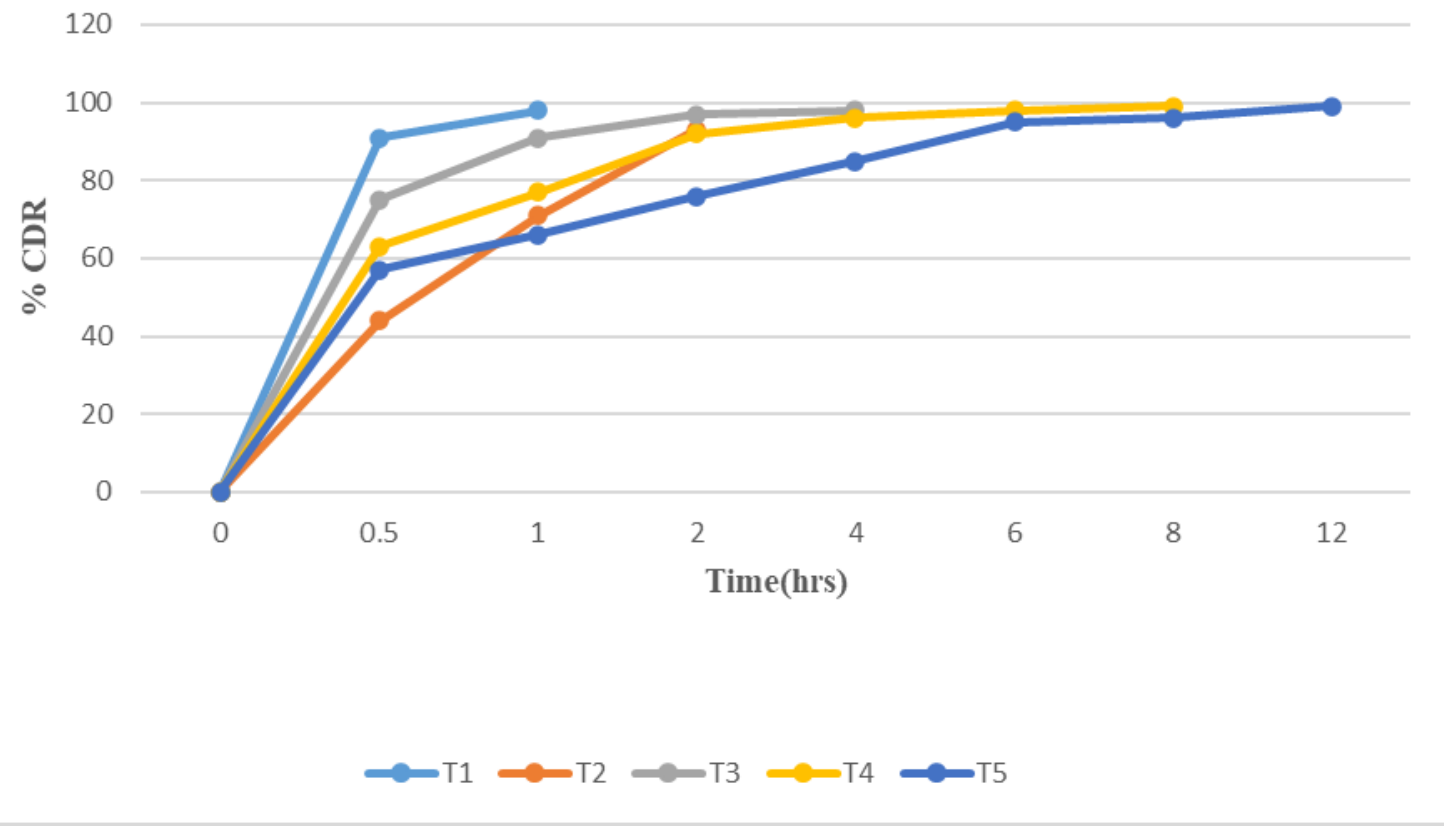

\section{CONCLUSION}

In the present study an attempt was made to formulate and evaluate self-micro emulsifying sustained release pellets for breast cancer. In vitro release profile results indicate that increasing the Carbopol polymer concentration increases the sustained release property of the drug. Based on the in vitro release, the formulation T5 was finalized and selected as optimized formulation, since it enhances the solubility, bioavailability and provides maximum sustained release profile of 12 hrs to treat breast cancer.

\section{ACKNOWLEDGEMENTS}

This work was kindly supported by HLL Life Care Ltd. Trivandrum. The authors are grateful to KMCT College of Pharmaceutical Sciences, Kozhikode for providing all necessary facilities for conducting the research.

\section{Conflict of interest}

The authors of this study declare that there is no conflict of interest in the present research work.

\section{REFERENCES}

1. Sudhirkama et al. Formulation approaches for sustained release dosage forms. Asian J Pharm Clinresh. 2015; 8 (5):46-53.

2. Abdul Hadi et al. Formulation and Evaluation of Sustained Release Pellets-Filled Capsule of Glimepiride, International Journal of Universal Pharmacy and Life Sciences. March-April 2013; 3(2): 2249-6793.

3. Atef E, Belmonte AA. Formulation and in vitro and in vivo characterization of a phenytoin selfemulsifying drug delivery system (SEDDS). European journal of pharmaceutical sciences. 2008 Nov $15 ; 35(4): 257-63$.

4. Syed HK, Peh KK. Identification of phases of various oil, surfactant/co-surfactants and water system by ternary phase diagram. Acta Pol Pharm. 2014 Mar 1; 71(2): 301.

5. Bhandari V, Avachat A. Formulation and characterization of self-emulsifying pellets of carvedilol. Brazilian Journal of Pharmaceutical Sciences. 2015 Sep; 51(3):663-71

6. Tung NT et al. Development of solidified self-microemusifying drug delivery systems containing 1tetrahydropalmatine: design of experiment approach and bioavailability comparison. International journal of pharmaceutics. 2018 Feb 15; 537(1-2): 9-21.

7. Nepal PR et al. Preparation and in vitro-in vivo evaluation of Witepsol ${ }^{\circledR} \mathrm{H} 35$ based self-Nano emulsifying drug delivery systems (SNEDDS) of coenzyme Q10. European Journal of Pharmaceutical Sciences. 2010 Feb 19; 39(4):224-32.

8. Akhtar $\mathrm{N}$ et al. Self-nanoemulsifying lipid carrier system for enhancement of oral bioavailability of etoposide by P-glycoprotein modulation: in vitro cell line and in vivo pharmacokinetic investigation. Journal of biomedical nanotechnology. 2013 Jul 1; 9 (7):1216-1229. 
9. Khoo SM et al. Formulation design and bioavailability assessment of lipidic self-emulsifying formulations of halofantrine. International journal of pharmaceutics. 1998 Jun 1; 167(1-2):155-164.

10. Li P, Ghosh A et al. Effect of combined use of non-ionic surfactant on formation of oil-in-water micro emulsions. International journal of pharmaceutics. 2005 Jan 6; 288(1):27-34.

11. Nazzal $\mathrm{S}$ et al. Optimization of a self-nanoemulsified tablet dosage form of Ubiquinone using response surface methodology: effect of formulation ingredients. International journal of pharmaceutics. 2002 Jun 20; 240(1-2):103-14.

12. Onoue $\mathrm{S}$ et al. Novel solid self-emulsifying drug delivery system of coenzyme Q10 with improved photochemical and pharmacokinetic behaviours. European Journal of Pharmaceutical Sciences. 2012 Aug 15; 46(5):492-499.

13. Agarwal $G$ et al. Oral Sustained Release Tablets: An Overview with a Special Emphasis on Matrix Tablet. American Journal of Advanced Drug Delivery. 2017; 5(2):64-76.

14. Chopade VV, Chaudhari P. Development and evaluation of self-emulsifying drug delivery system for lornoxicam. IJRDPL. 2013 Apr; 2(4):531-537.

15. Chen Kuang et al. Preparation and evaluation of duloxetine hydrochloride enteric-coated pellets with different enteric polymers, Asian journal of pharmaceutical sciences. 2017; (12): 216-222.

16. Dr. B.Bhatt, Prof. S.S. Agrawal. Pharmaceutical Technology Capsules, Delhi Institute of Pharmaceutical Science and Research Sector, New Delhi.2007; page no: 1 -26.

17. D.C. Hicks et al. Extrusion and spheronizing equipment (Ed.), Pharmaceutical pelletization technology, Marcel Dekker, New York 1989; page no: 71-101.

18. Eberl M. M et al. Patients with a Family History of Cancer: Identification and Management. JABFM. 2005; (18): 211-217.

19. Fletcher S. W. Patient information: Risk factor for breast cancer. Up-To-Date. 2008. Jan 29, [20 Mar 2010].

20. Huang X, Aslanian RG. Case Studies in Modern Drug Discovery and Development. John Wiley \& Sons.19 April 2012; page no: 392-394.

21. Mirkin S, Pickar JH. Selective estrogen receptor modulators (SERMs): a review of clinical data, Maturitas. Jan 2015; 80 (1): 52-57.

22. Mihir K Raval et al. Formulation and evaluation of sustained release enteric-coated pellets of budesonide for intestinal delivery, International Journal of Pharmaceutical Investigation. 2013; 3(4): 203-303.

23. Nekkanti V et al. Solid self-microemusifying formulation for candesartan cilexetil. Aaps Pharmscitech. 2010 Mar 1; 11(1): 9-17.

24. Shukla prachi et al. A Review of on Self Microemusifying Drug Delivery Systems, International Research Journal of Pharmacy. 2012; 3: 1-6.

25. Shafiq $S$ et al. Development and bioavailability assessment of ramipril nanoemulsion formulation. European Journal of Pharmaceutics and Biopharmaceutics. 2007 May 1; 66(2): 227. 